\title{
When Therapists Do Not Know What to Do: Informal Types of Eclecticism in Psychotherapy
}

\author{
Diego Romaioli ${ }^{1 \bowtie}$ and Elena Faccio ${ }^{2}$
}

\begin{abstract}
Eclecticism usually arises from the perception of one's own theoretical model as being inadequate, which may be the case in situations of therapeutic stalemate. In need of new strategies, therapists criticize their own approach and take eclectic knowledge onboard. The goal of this qualitative study is to explore basic elements of this informal knowledge, with reference to the theory of social representations and points of view. Episodic interviews were conducted with 40 therapists. Results confirmed that clinical knowledge often turns eclectic, showing different styles of reorganization; a social co-evolution model will be pointed out to explain this personalization of one's own approach. The results achieved might contribute to the amelioration of the therapeutic awareness of one's own knowledge structure and the use of eclecticism in carrying out therapies, leading to significant benefit in treatment effectiveness.
\end{abstract}

Keywords: psychotherapy, eclecticism, social representations, points of view, qualitative methodology

Clinical intervention is increasingly structured according to an eclectically oriented style of psychotherapy; such eclecticism is encouraged as a way that allows the therapist-through the use of a different theoretical frame-to expand the possibility of understanding the client's issues better (Slife, 1987).

In the literature, three kinds of eclecticism have been described, all supported by the shared belief that clinical practice is more complex than theory and, as such, requires a pragmatic approach from the therapist; such an approach is considered necessary to compensate for the limited knowledge categories that each one-sided theoretical approach provides. The first form of eclecticism is called theoretical integrationism (Arnkoff, 1995; Held, 1995; Prochaska \& DiClemente, 1984), which combines different theories without worrying about possible epistemological incompatibilities: Its aim is to increase the number of concepts available to the therapist for clinical investigation. A second form of ec-

\footnotetext{
1 Department of Philosophy, Pedagogy and Psychology, University of Verona, Italy.

${ }^{2}$ Department of Philosophy, Sociology, Education and Applied Psychology, University of Padua, Italy.

Correspondence concerning this article should be addressed to Diego Romaioli, Department of Philosophy, Pedagogy and Psychology, University of Verona, Ldg. Porta Vittoria 17, 37129 Verona, Italy. Email: diego.romaioli@univr.it
}

lecticism is called technical eclecticism (Lazarus \& Beutler, 1993; Lazarus, Beutler, \& Norcross, 1992; Norcross, 1986) and prescribes the use of the most promising techniques after having proven their efficacy through scientific research studies (Beutler \& Clarkin, 1990). Making use of objective methods and considering therapeutic techniques as mere instruments to be used, such an approach makes it acceptable to extrapolate such techniques from their conceptual frameworks; that is, from the specific theories from which they originally stemmed (Patterson, 1989). The third kind of eclecticism, widely criticized by the eclectic-oriented movements themselves, does not provide any reasoned response to the topics and issues reported by clinicians and, as a consequence, is named unsystematic eclecticism. This kind of eclecticism favours an instrumental use of different theories and techniques in therapy, yet it does not establish any explicit criterion through which to select from among different components of such theories (Gilliland, James, \& Bowman, 1994).

Beyond the official, formal categories of eclectic approaches to therapy, the goal of the present work is to explore how therapeutic knowledge is organized when it is most informally put into effect (Hansen, Randazzo, Schwartz, Marshall, Kalis et al., 2006; Romaioli \& Contarello, 2012). Assuming that psychotherapists trained within the same approach 
consider input from other theoretical models in a similar way, we compare their narratives about perceived implications of the practice of the chosen clinical model and their strategies to solve impasse situations and more effectively investigate their attitudes toward eclecticism.

On this premise, methodological and theoretical integration, revision and personalization of models can be envisioned as an everyday practice, yet not always recognized and discussed with adequate attention within the broader scientific community (Hoshmand \& Polkinghorne, 1992).

\section{Conceptual Framework}

The therapeutic intervention cannot be considered as a derivation of a knowledge system that precedes it and from which it is separated (Romano \& Quaglino, 2001). What instead has to be recognized is the pragmatic character of therapeutic contexts, and then the vision of the therapist should be questioned as an expert who applies his personal baggage of knowledge, learned at another time and in another place than the clinical practice (Salvatore, 2006). In contrast, the therapeutic action always takes place on the basis of a community of practice: The therapist's knowledge is continually being reorganized because of the heritage of distributed expertise of which the expert is part; these assets result from the incessant labor of informal negotiation of meanings that distinguishes every circumstance of social practice (Iannaccone $\& \mathrm{Li}$ gorio, 2001; Valsiner \& van der Veer, 2000). Professional contexts require therapists to organize and adapt the categories of knowledge available to the unique needs of the situation they are managing.

We also need to consider that each theoretical approach sustained by the scientific community is made up of a shared symbolic system that is intertwined, with different degrees of diffusion, with the theories of common sense (see Moscovici, 1961), which provide the interpretative frameworks through which people orient themselves in the management of interpersonal relationships and problematic situations (Berger \& Luckmann, 1966). In these circumstances, it is likely that therapists may tend to incorporate into their own repertoire of professional theories, common sense theories on which they are experts in terms of participating in a social context and sharing a specific cultural frame (Gergen, 1994, 2006). Specialized skills are constantly rearranged within systems of knowledge which are more complex than those prescribed by each psychotherapeutic school (see Hoshmand \& Polkinghorne, 1992; Slife \& Reber, 2001).

The present research emerges from a social constructivist perspective (Flick, 1998) and refers to social representations theory (Farr \& Moscovici, 1984; Wagner \& Hayes, 2004). The distinction between social representations (SR) and points of view
(POV) is relevant to the present work: The former have been defined as the abstract and standard knowledge background of a social group; the latter consist of a contribution by the individual's cognitive elements (Tateo \& Iannacone, 2011; Valsiner, 2003). Social representations are conceptualized as systemic phenomena in themselves, not reducible to individual minds (Chryssides et al., 2009; Harré, 1984; Jovchelovitch, 2007), constituting a social reality sui generis (Moscovici, 2000). In contrast, a point of view constitutes a "personal representation" (Breakwell, 2001) and can be defined as a social actor's outlook toward some object or event "expressed as a claim, which can be supported by an argument based on a system of knowledge from which it derives its logic" (Sammut \& Gaskell, 2010, p. 49). Points of view are a social psychological phenomenon, held to be the individual counterparts of social representations.

As highlighted by Tomm (1987), a therapist's decisions during a therapy session depend on both his or her development as a professional and on his or her personal history; consequently, the therapist's POV also includes idiosyncratic pieces of knowledge that do not originate from the therapist's reference theory. Namely, the POV includes knowledge the individual borrows from other symbolic contexts, creatively changing it into strategies for a deeper understanding of what happens in his or her daily practice (Jovchelovitch, 2007). Therefore, SR form a widely shared corpus of knowledge that can be roughly categorized according to the formal theoretical reference models (see von Cranach, Mugny \& Doise, 1992); however, POV are allocated at different levels of therapists' knowledge structure, resulting either in original production or in the eclectic combination of pieces of knowledge that originate from different psychological models or other branches of knowledge (Romaioli, 2012). As Norcross (Norcross \& Goldfried, 2005, p. 1593) pointed out, even if "most therapists have been and continue to be trained in a single approach. ... Most therapists gradually incorporate parts and methods of other approaches once they discover the limitations of their original approach."

In facing clinical difficulties, therapists are induced to take a stand and view their clinical actions from another perspective. In this way, limitations of one point of view are transcended by including the possibilities offered by other theories, especially when these are encysted in discursive practices of common sense, and might be "translated" in operative terms also by non-experts, both people and professionals not having received specific training in that specific field (Faccio, Centomo, \& Mininni, 2011; Faccio, Cipolletta, Dagani, \& Romaioli, in press).

Therapists become open to more alternatives than their own unaided point of view makes possible. The extent to which a therapist's point of view is open to different ways of conceptualizing, there- 
fore, has far-reaching consequences on therapy: It determines the extent to which creative, positive solutions to clinical impasses may be realized. Points of view may be open to others' logicality or they may be open to others' perspective, but not to others' frame of reference. Or they may be closed to others' points of view altogether (Porpora, 2001; Tsirogianni \& Gaskell, 2011). Adopting a point of view that is more or less open to alternative theories allows therapists to gain clinical efficacy, optimizing positive contributions from different therapeutic traditions.

\section{Aims of the Study}

This work intends to shed light on the way in which the knowledge systems that support therapeutic action are structured and organized (Romaioli \& Contarello, 2012). More specifically, the structure of knowledge will be investigated at the level of points of view; that is, by reconstructing the whole set of meanings the participants express and that have no formal allocation in the symbolic universe of theoretical models of reference. Our goal is not only to explore the conditions inviting therapists to shift from the operational criteria suggested by their theoretical orientation, but also to reconstruct the organization of knowledge that enables therapists to manage clinical practice under such conditions. More specifically, the POV we have investigated can be identified as:

- Narrative reports that justify and legitimate eclectic practice;

- Integrations among different operational models and personal re-elaborations of psychological models for clinical intervention.

\section{Method}

\section{Participants}

The research design is a comparative one and is essentially based on a qualitative methodology (Elliott, Slatick \& Urman, 2001; Flick, 2006), mainly linked to the tradition of grounded theory (Glaser \& Strauss, 1967) revised in a social constructivist perspective (Charmaz, 2006). Data was collected through an interview protocol conducted with a sample of 40 psychotherapists, both in private practice and public institutions.

Four operational models were consideredcognitive-behavioral, constructivist, psychodynamic, and systemic-relational-forming four groups, each containing eight women and two men. The group of cognitive therapists refers to the psychotherapeutic models derived from Beck's theories. The constructivist therapists explicitly link to Kelly's theory of personal constructs. The psychodynamic therapists mainly belong to the Freudian and Kleinian school. The group of systemic-relational therapists refers to the Milan school. Models were selected based on their diffusion in the research areas (Northern Italy) and on belonging to wellestablished therapeutic traditions. However, there was no conceptual constraint to prevent the same research protocol being successfully applied to other traditions.

Therapists were recruited through an advertisement requesting collaboration published on the official site of the Board of Psychologists of the Veneto region. The prerequisites for the subjects of the sample were a minimum of three years spent in clinical practice, and an affirmation that they follow one of the above-listed psychotherapy models and not-at least not explicitly-an eclectic or integrationist approach. Participants were divided into groups according to their theoretical orientation and other variables we considered relevant to reconstructing the knowledge structures involved in planning therapeutic action. The most important are (see also Table 1 ):

1) Age (ranging from 31 to 66, with an average age of 42).

2) Professional training: orthodox or pluralist (where the professional attended post-graduate courses based on theories different from his or her theoretical orientation).

3) Whether personal therapy had been undertaken with a therapist who shared-or did not sharethe participant's theoretical orientation.

4) Participation in team meetings with colleagues with a different theoretical orientation.

5) Professional experience, measured in years of clinical practice as a professional (ranging from 3 and 27 years, with an average of 12 years of clinical practice).

\section{Episodic Interviews}

To collect data, episodic interview protocols were used: This method draws its basic assumptions from narrative psychology (Riessman, 1993) and from episodic and semantic memory studies (Tulving, 1972). We chose episodic interviews as they are considered especially well suited to the unraveling of inner discrepancies and contradictions in the speaker's arguments. The episodic interview is also intrinsically advantageous as it already constitutes a triangulation, a procedure to obtain a better understanding by using different methods: The episodic interview enables a methodological triangulation by using sets of differently structured questions (Flick, 2000).

The introduction to the interview was: "In the following interview, you will be requested to describe situations you have experienced within your clinical practice; you will be asked to focus on the issues you have found significant in a specific case." During this first stage, the participant was explicitly 
Table 1. Composition of the sample of psychotherapists

\begin{tabular}{|c|c|c|c|c|c|c|c|c|c|c|c|c|c|c|c|}
\hline & \multicolumn{3}{|c|}{$\begin{array}{l}\text { Cognitivist } \\
(n=10)\end{array}$} & \multicolumn{3}{|c|}{$\begin{array}{c}\text { Psychodynamic } \\
(n=10)\end{array}$} & \multicolumn{3}{|c|}{$\begin{array}{l}\text { Systemic } \\
(n=10)\end{array}$} & \multicolumn{3}{|c|}{$\begin{array}{l}\text { Constructivist } \\
\qquad(n=10)\end{array}$} & \multicolumn{3}{|c|}{ Total } \\
\hline & $n$ & $\begin{array}{c}\% \\
\text { model }\end{array}$ & $\begin{array}{c}\% \\
\text { total }\end{array}$ & $n$ & $\begin{array}{c}\% \\
\text { model }\end{array}$ & $\begin{array}{c}\% \\
\text { total }\end{array}$ & $n$ & $\begin{array}{c}\% \\
\text { model }\end{array}$ & $\begin{array}{c}\% \\
\text { total }\end{array}$ & $n$ & $\begin{array}{c}\% \\
\text { model }\end{array}$ & $\begin{array}{l}\% \\
\text { total }\end{array}$ & $n$ & $\begin{array}{c}\% \\
\text { model }\end{array}$ & $\begin{array}{c}\% \\
\text { total }\end{array}$ \\
\hline \multicolumn{16}{|l|}{ Context } \\
\hline public & 6 & 60.0 & 15.0 & 4 & 40.0 & 10.0 & 8 & 80.0 & 20.0 & 1 & $\begin{array}{l}70.0 \\
10.0\end{array}$ & $\begin{array}{r}2.5 \\
2.5\end{array}$ & $\begin{array}{l}21 \\
19\end{array}$ & 47.5 & 47.5 \\
\hline \multicolumn{15}{|l|}{ Training } & 47.5 \\
\hline pluralistic & 4 & 40.0 & 10.0 & 6 & 60.0 & 15.0 & 8 & 80.0 & 20.0 & 3 & 30.0 & 7.5 & 21 & 52.5 & 52.5 \\
\hline \multicolumn{16}{|l|}{ Experience } \\
\hline 3-10 years & 8 & 80.0 & 20.0 & 3 & 30.0 & 7.5 & 4 & 40.0 & 10.0 & 4 & 40.0 & 10.0 & 19 & 47.5 & 47.5 \\
\hline$>10$ years & 2 & 20.0 & 5.0 & 7 & 70.0 & 17.5 & 6 & 60.0 & 15.0 & 6 & 60.0 & 15.0 & 21 & 52.5 & 52.5 \\
\hline \multicolumn{16}{|c|}{ Personal therapy } \\
\hline yes & 0 & 0.0 & 0.0 & 10 & 100.0 & 25.0 & 1 & 10.0 & 2.5 & 5 & 50.0 & 12.5 & 16 & 40.0 & 40.0 \\
\hline hybrid & 1 & 10.0 & 10.0 & 0 & 0.0 & 0.0 & 8 & 80.0 & 20.0 & 0 & 0.0 & 0.0 & 9 & 22.5 & 22.5 \\
\hline no & 9 & 90.0 & 90.0 & 0 & 0.0 & 0.0 & 1 & 10.0 & 2.5 & 0 & 12.5 & 12.5 & 15 & 37.5 & 37.5 \\
\hline
\end{tabular}

asked to talk about personal events regarding his or her clinical experience. Questions included: "Can you describe your client's changes during therapy and how you organize therapy? Can you describe a typical case from your own experience, showing how such an evolution might be explained?" The purpose of these questions is to have the therapist recall actual situations in which they played an active role, bringing out the specific context of his or her clinical experience and the in-generated meanings.

During the second stage, a discussion of topics that emerged from the specific interaction was encouraged (Hermanns, 2004). The question for a therapist expressing theoretical constructs pertaining to a model different from the training orientation model: "How would you describe this issue in cognitive behavioral terms? Your orientation is cognitive behavioral, yet you use a systemic approach; how does it fit in with your reference model?" Such questions could elicit the clinicians' arguments to justify eclectic practice. During the conversation, the therapist was invited to speak about critical areas he or she identified of his or her theoretical orientation:

- Can you tell me about a situation where you had to face the fact that your client's problem still persisted? How would you explain such an impasse?

- Considering your clinical experience, are there issues in your theoretical orientation that, in your opinion, could be expanded, integrated, or modified to improve clinical practice?

The aim of this line of questioning was to make it clear how theoretical assumptions were rendered within clinical practice, pointing out to what extent they suited the actual clinical situations. Whenever the therapist offered arguments going against his or her own paradigm, the interview protocol called for in-depth analysis of how the clinician could cope with the critical situations he or she reported. To a therapist reporting that his or her cognitive training does not enable him or her to deal with the client's emotional issues, the question was asked: "Therefore, in these years what did you do when you had to cope with your client's emotional issues? How did you integrate these aspects?"

Thus, the organization of therapeutic knowledge could be explored at the level of point of view. Then, the study investigated what kind of knowledge enabled the clinician to justify the use of different theories and how he or she explained it. To a therapist with an eclectic training: "You had analytic psychotherapy and systemic training; I would like to know how you could integrate both perspectives into actual practice. If you did, how did you do it? If you shifted from one to another, on what assumptions?"

On average, the interviews lasted one-and-a-half hours. They were conducted by the first author in the therapist's workplace. The textual material collected consists of about 75 hours of audiotapes, transcribed verbatim into word documents. The interviewer has received training in the field of epistemology of psychology and also practices clinical activity with particular reference to constructionist psychotherapies.

\section{Analysis Criteria}

The textual material collected was subjected to a thematic content analysis using NUD*IST software. 
The whole codification procedure was agreed upon by the author along with two other researchers, each of whom gave an evaluation of the relevance of an identified meaning aspect (code) and the content of the texts analyzed (Strauss \& Corbin, 1998). There was $90 \%$ agreement rate amongst the researchers when judging how to categorize the texts.

We were able to share a schematic account of the main elements emerging from the interviews (structure laying technique) with some of the therapists to validate the researchers' codification (Flick, 2006; Hill et al., 2005).

The code frame was then adopted as the index of a knowledge structure (Charmaz, 2006); afterwards, the knowledge structures that emerged from the therapists' answers were compared: (a) with the theories of their reference group and (b) with the theories of other groups to discern their similarities and differences. Therefore, for each therapist, we were able to reconstruct the set of codes that belonged to the theory of their reference group and those that, on the other hand, indicated the use of more personal concepts taken from orientations that were not theirs.

The textual material collected was carefully studied to identify: (a) possible critical issues in the reference model; (b) strategies the therapists generated to overcome difficulties within clinical practice; and (c) possible ways of integrating and justifying different theoretical perspectives or kinds of practice.

\section{Results}

\section{Critical Aspects in the Application of One's Therapeutic Theoretical Frame}

During the interview, therapists were invited to describe the limits (if present) found in applying the theoretical orientation model into clinical practice and the ways they could overcome such limits. Focusing on such critical issues enabled us to identify clinical circumstances that could require a therapist to use representations different from his or her training and, more broadly, from the SR of the orientation model. The most frequently reported issues did not actually pertain to the formal model's own limits but its informal application in practice and the reinterpretation of the model by the therapists interviewed to make it more easily applicable.

The cognitivist group reported difficulty coping with the clients' emotional issues (reported by $40 \%$ of therapists in the group) and a difficult applicability of cognitive behavioral techniques to obscure or not well-defined issues, or connected to a so-called existential sphere.

The constructivist group reported few limits with regard to the applicability of the model; a possible reason could be that the constructivist theory is considered abstract enough to be applicable in different circumstances without dramatic revisions
(Kelly, 1955). The members of this group, as described later, mainly expressed a kind of knowledge defined not as eclectic but as syncretistic. Nevertheless, one constructivist therapist highlights the difficult applicability of her model in the public context; another therapist points out the need to expand studies and research in the field of couple therapy.

Psychodynamic therapists mostly agree $(70 \%)$ on poor applicability of their reference model in situations differing from the private context; they also describe urgent or highly incapacitating conditions as quite difficult to deal with. The fast pace imposed by social changes had a modifying effect both on the questions that patients ask therapists and on institutional practice itself, with less time and attention devoted to the requirements of the setting and to the organization of the time schedule-as they are supposed to be, according to psychodynamic orientation.

Therapists in the systemic relational group (60\%) mostly mentioned problems with carrying out individual therapy, reporting that they possess limited knowledge for dealing with the personal, introspective domain, a deeper understanding of which they consider to be necessary within some specific clinical situations.

\section{Overcoming Difficulties in Carrying Out Clinical Practice}

Whenever a therapist reported shortcomings in the use of his or her theoretical frame of reference, the interview protocol prescribed a set of questions to probe how the therapist could overcome the restrictions perceived in carrying out clinical practice-both from an operational and conceptual point of view. Very often, the therapist's response entailed letting go of the situation and either referring the client to a colleague or institution, or else making massive use of supervision as a valuable resource. In other cases, however, therapists reported episodes where personal initiative proved relevant, creative and decisive to solve their problem, actually enabling them to perform original interventions, very often based on an eclectic pattern of practice and (therefore) of the therapeutic knowledge by which it is supported.

As has already been suggested by von Cranach (1992), our findings indicate that therapists utilize inferences from representations unrelated to the $S R$ from their theoretical perspective but that derive especially from psychodynamic and cognitive behavioral theories (Hickman, Arnkoff, Glass, \& Schottenbauer, 2009). Such points of view are employed by therapists in particular when therapy is at a stalemate. Representations from a psychodynamic and cognitive theoretical background are prominently used by therapists from different theoretical perspectives where the client has not reported any change-usually a good reason to broaden the rep- 
ertory of possible interpretations.

The following concepts are listed according to the frequency with which they are used by therapists to explain an unsuccessful therapy outcome. Such interpretations were used very often by clinicians who followed different theories from those these concepts belong to: "inner conflict" (cited by $37 \%$, not by psychodynamic therapists), "reinforcement" (cited by 33\%, not by cognitive-behavioral therapists), change seen as a "conditioning/learning" (17\%), the concepts of "defense" (17\%), symptom "shifting" and its "cover" effect (17\%).

\section{Knowledge Structure and Management of Eclecticism in Psychotherapy}

An eclectic knowledge structure was exhibited by $57.5 \%$ of therapists. They were divided into three different groups according to the different management of techniques and concepts belonging to paradigms that were different from their theoretical orientation.

The first group consisted of $12.5 \%$ therapists who develop a meta-knowledge that organized the use of different theoretical concepts at a subordinate level: The presence of at least two reciprocally discordant elements generated a novel representation that reconciled previously incompatible concepts. In other words, some therapists built a superordinate level of justification for the different eclectic procedures used during the therapy session. In terms of Norcross \& Goldfried's (2005) definitions, this group seemed to intuitively achieve a kind of theoretical integration where the synthesis of multiple theories was engaged. The content analysis tables were subjected to a Chi-square test using the program SPAD (Systeme Portable pour l'Analyse des Données; Lebart, Morineau, \& Becue, 1989): The pluralist formation emerged as the only significant variable among those analyzed for the group that constructs an original knowledge system. The fact that they were able to study the theoretical specifications of different intervention models during their training is likely to have enabled the therapists to integrate them into a fuller, more original perspective. In fact, from a certain point of view, such systems can possibly foresee the future evolution lines for psychological models. Participants of this group (see Table 2) were able to develop a "fusion of horizons" (Gadamer, 2000, p. 398), a process that led to a joint creation of a new understanding through the merging of different theoretical perspectives (Gadamer, 1989a, 1989b; Tsirogianni \& Andreouli, 2011). An interview example follows when speaking about psychodynamic and cognitive theories:

Actually, they are different but have contiguous features. The former [psychodynamic theory] works in depth, whereas the latter [cognitive theory] works on the surface and at a subconscious level. Cognitive behaviorist therapy reorganizes the cognitive dimension, that is, one works in one way and the other in another way, but they are both valid. I am open to all theories, I like to know everything, what one [theory] says, what another one says, I like to learn. They are different filters, one works more at an unconscious level ... but I also ought to think at a conscious level, that is at a rational level; thus, they are two different levels, and I always have to take both into account. That is more or less how I work, and I realize that it works (Interview 14; female; psychodynamic).

Deviations from the SR of the reference group are usually supported by a point of view that provides a normative system for therapeutic action. Precisely because such a point of view is related to higher individual variability in action, it needs a higher level of conscious representation and more numerous arguments and justifications as well (see von Cranach, 1992). By investigating this conceptual level, we found the therapists of this group mainly refer to the category of theoretical justifications for eclecticism: The eclectic option becomes practicable after a specific evaluation of the status of theories, often seen as lenses to be used together, because they enable us to see different parts of the same object.

There is a whole set of other theories that help you see the problem from different perspectives, not to make a hotchpotch but to consider the same element from different viewpoints. A person possesses dynamic elements, facets that can be seen from a cognitive perspective; we can intervene at a behavioral level for some steps and use a non-directive mode where, by pressing the issue, you can do more harm than good (Interview 26; male; cognitivist).

The second group was the most numerous and consisted of $37.5 \%$ of the 40 therapists. They tended to develop pluralist representation systems that do not overlap and that enable a therapist to perform different interventions according to the specific client's request. In this regard, the concept of cognitive polyphasia (see Table 2) can explain how a point of view can oscillate between different belief systems, thus enabling him or her to develop distinct courses of action that are tightly intertwined and with reciprocally antithetical representations (Jovchelovitch, 2008; Moscovici, 1961; Wagner, Duveen, Verma, \& Themel, 2000; Wagner \& Hayens, 2004). In this case, the belief system is structured according to a set of representations that are independent of each other; actually, cognitive polyphasia is an indicator of the presence of a complex representation system that is not organized at a super-ordinate level but instead operates through the activation of specific interpretive modes, depending on the issues the client has brought to therapy. Specifically, the therapist uses the typology of the problem presented as a discriminating factor 
to choose a specific mode of practice. In our sample, the participants who resulted significant in the Chi-square test were those who had a hybrid therapy that was different from their orientation. Working in public structures proved to be almost significant. In Norcross \& Goldfried's (2005) distinctions, participants of this group adopted a kind of technical eclecticism where the use of various techniques is supported without regard to the theory that spawned them. Reflection on how theoretical models may be integrated is limited, and the clinicians use them in practice only when specific situations occur. As a matter of fact, these therapists tended to substitute most often their reference paradigm for another one that is considered better suited at that moment to deal with the difficulty the client has brought to therapy. The most significant dimension to cause important changes in the therapist's representation system seems to be the abstract/concrete polarity: That is, when dealing with well defined, disabling, and concrete problems, therapists chose techniques centered on symptom resolution-seen as faster and immediately applicable. On the other hand, when confronting relational or existential issues, therapeutic action strictly complied with the guidelines of other paradigms. In the following excerpt, a therapist describes a situation that induced him to change his approach with clients in therapy sessions by shifting, for instance, from a psychodynamic mode (centered on listening and relationship) to a cognitive mode (more directive and symptom centered).

\begin{abstract}
Certainly, whenever patients ask to be given support in controlling symptoms and avoid opening a dimension of emotional understanding... on the basis of the patient's request, I will use more or less the psychoanalytic method. . . . I tried to investigate the relational dimension through an exhaustive anamnesis the patient allowed me to gather, but he or she was reticent about his or her request, I mean, he or she tried to bring the attention focus of our therapeutic relationship back to his or her specific problem; I complied with his or her request, trying to use techniques referring to cognitive theory, such as systematic desensitization, first trying to give the patient a deeper knowledge of the phobic object, then trying to have him or her study it and approach it (Interview 8; male; psychodynamic).
\end{abstract}

Regarding justifications evoked for eclecticism, we found this group mainly referred to value-centered and pragmatic categories: In the first case, the eclectic option was considered as a need related to the clinician's personality. Therapists often identified with values such as curiosity and tolerance that were expressed through an open, experimental attitude and a blend of new, enriching, diverse practices. In the second case, the eclectic option was often associated with remarks on how important it is to use more than one theory for the patient's good, pointing out that clinical practice is much more complex than theory.
I work as a psychodynamic therapist, but I also use other techniques; I am not a closed-minded therapist. ... Thus, [I go] beyond conventions, I am actually against conventions. At least, I usually do it this way; however, I still continue to read and study, just because I am curious. ... Anything can help, I can manage to aggregate everything (Interview 12; female; psychodynamic).

The third group's perspective could be defined, in line with Norcross \& Goldfried's (2005) distinctions, as a form of assimilative integration; that is, it proposes the use of one model's conceptual frame in which revised procedures from other models could be inserted. Although such a mode of action implies a form of eclecticism, both the therapeutic action and the evaluation of the strategy's effectiveness still refer to one theoretical background. Therefore, assimilative integration is a conceptual operation that enables therapists to elaborate different techniques inside a common theoretical frame. Participants of this group seem to express a dialogical point of view (see Table 2)-one that acknowledges the existence of other orientations but retains its logic as a superior form, so there is only a partial perspective taken from another theory without adopting another frame of reference. Belonging to the constructivist group was found to be a significant variable to single out subjects who utilize this mode to organize their therapeutic knowledge. In addition, because of the history of the rise of constructivism in social sciences itself, therapists in this group used reflections of an epistemological nature more often-reflections with a high level of abstraction that enabled them to carry out a rewriting of other methods within their own reference model.

In constructivism, there is a facet related to phenomenology, a facet related to systemic theories; if we want to refer to other theories, there is a facet related to relationships, a facet related to the body. [...] If we want to pick something up from psychodynamic theory, there is the unconscious theory: Therefore, from my own perspective, I would say in constructivism, we can find all these facets. Such a widening of my perspective depends partly upon my training, which in my postgraduate school [years] made me plan to learn how to use other, different tools and integrate them into a wider vision (Interview 36; female; constructivist).

\section{Psychotherapy between Dogma and Rigor}

Although a large preponderance of therapists exhibit a knowledge structure mainly based on eclecticism, some participants (42.2\%) expressed an orthodox system of beliefs (Deconchy, 1984), built up according to the theoretical assumptions typical of the kind of psychotherapy they practiced. Surprisingly, the lack of contradictions in the semantic core of representation predominates in therapists 
Table 2. Correspondence between forms of eclecticism and points of view that sustain them (informally)

\begin{tabular}{llll}
\hline Structure of Knowledge & Forms of Eclecticism & Types of Points of view & Characteristics \\
\hline First type & Theoretical integration & Fusion of horizons & $\begin{array}{l}\text { Combination of different } \\
\text { models that leads to a new } \\
\text { understanding }\end{array}$ \\
Second type & Technical eclecticism & Cognitive polyphasia & $\begin{array}{l}\text { Use of several models in } \\
\text { absence of an } \\
\text { epistemological overview } \\
\text { Third type }\end{array}$ \\
Assimilative integration & Dialogical point of view & $\begin{array}{l}\text { Other clinical models are } \\
\text { used as subordinated to the } \\
\text { main } \\
\text { Other clinical models are }\end{array}$ \\
Fourth type & No Eclecticism & Monological point of view & $\begin{array}{l}\text { Othet considered at all } \\
\text { not }\end{array}$ \\
\hline
\end{tabular}

who did not undergo personal therapy. This is probably due to the fact that those therapists who do not re-examine their own personal history under the lens of professional categories (as happens in therapy) are able to keep their professional knowledge more distinct from personal common sense awareness. Moreover, regarding the contents, they have arguments to belittle other theoretical orientations, as they have developed critical thinking on the subject. The more such a belief is articulated, the more the clinician will keep within his or her own theoretical integrity. Respondents of this group seem to present what has been called a monological point of view (see Table 2), in which therapists do not grant any legitimacy to alternative points of view and dismiss alternative orientations as wrong or bad (Sammut \& Gaskell, 2010). An excerpt follows as an example:

This is actually one of the typical features of constructivism; whereas other theories deal with all that is built by the patient, constructivism is not concerned with what is being built but with how it is built, with the process through which one shapes his or her stories.... Yes, because constructivism is not a therapy using frustration, for instance, like psychoanalysis, where one [the therapist] plays with silence; it is not a behavioral cognitive therapy in a classical sense, where one operates on the other person, and the other is not conscious of what you are doing, as in strategic therapy where you perform some actions, the other person performs some actions as well, but does not know what is going on. ... Therefore, first I agree with it, because this [process] is aimed to set the person free, instead of jailing him or her inside diagnoses, situations, childhood traumas, defense mechanisms and the like (Interview 22; female; constructivist).

\section{Discussion}

Psychotherapy is historically characterized as a strongly plural field, animated by schools of thought operating as self-referential systems (Carli,
1987), able at the same time to become theoretical paradigms. However, the internal variability of conceptions within each school of thought tends gradually to increase and to be more relevant than that between schools (see Salvatore, 2006).

According to the interviews collected, the therapists' knowledge systems seem to be organized into dimensions of meaning that are definitely more articulated than the theoretical frames therapists learned in psychotherapy schools, suggesting that therapeutic activity could actually be carried out as an active, endless elaboration of different knowledge domains-professional, social, and personal-in which an individual participates (Roberts, 2006; Romaioli, 2012). Actually, it often happens that therapists are not always consistent with such theoretical assumptions when reporting on clinical cases, despite expressing a formal agreement with their original theoretical orientation.

With regard to therapeutic work, we found that eclectic issues predominate both in therapists that report a pluralist training and therapists who followed personal therapy routes characterized by a theoretical orientation different from their own training. Such patterns actually invite an evolution of knowledge structure according to unconventional, more open lines informed by eclecticism. Such knowledge structures, however, are endlessly built and confirmed but also reviewed and modified within communicative exchanges among individuals (Gergen, 2006; Romaioli, Faccio, \& Salvini, 2008). In fact, having the opportunity to discuss their activities with colleagues apparently affects therapists both in their organization and expansion of their knowledge systems. A considerable inclination to maintain an eclectic attitude, actually, is found in therapists who worked either in institutional practice, teamwork, or had the opportunity to talk often with professionals of different theoretical orientations. Such moments offer therapists a chance to negotiate meanings by discussing the therapeutic process with colleagues and allow them to 
participate in new, pluralistic, symbolic universes.

With regard to the above, we can also recall the fact that points of view provide interpretive outlines by organizing individual action and permitting communication and ordered interactions. The relationship between the formation of such points of view and the above-mentioned conditions is bidirectional and not causal; whereas the former organize themselves on the basis of social interaction processes taking place in different contexts, social interaction itself can take place through the structuring of such points of view. Applying the social co-evolution model (Thommen, Amman, \& von Cranach, 1988; von Cranach \& Harrè, 1992) to psychotherapeutic theories, we could say that the SR on which they are based follow a historical evolution, according to both society's structural changes and different individual elaborations that become points of view (Moscovici, 1976). We can outline the relationship between SR and points of view as a circular process: Within social interactions with colleagues and institutions, as mentioned, professionals tend to reorganize their knowledge systems, not only according to the SR of their reference group (in this case, to the theoretical orientation of their training) but also on the basis of a general knowledge in psychology and implicit theories coming from both common sense and personal experience. Through individual action, the group's SR are replicated, materialized, and made tangiblebut also criticized, expanded on, and revised in the unraveling of clinical practice. In fact, among the members of the same group, only a limited consensus can exist with regard to the reference SR's organization; this can elicit conflicts, contradictions, and debates that invite social change. In this case, such a process can lead to modifying the official SR from psychotherapy theoretical models, closing the circle of reciprocal interaction among individual and social levels (see Figure 1).

\section{Conclusions}

The progressive internal differentiation within models is leading to a gradual decrease of the boundaries between theoretical approaches and is favoring the emergence of innovative conceptualizations that move transversely, beyond the traditional rigidity that characterized clinical models in the past (see Salvatore, 2006). All this makes it possible to overcome the fragmentation of the traditional clinical psychological debate. Above all, this new framework enables professionals to understand the differences and the utility of different psychotherapeutic perspectives. Obviously, to optimize this pragmatic use of different theories and methods, the therapist must be able to move from one technique to another, or from one theory to another one, acknowledging that they constitute conceptual devices - and not real objects - that might become advantageous to the aims of therapy.

In this regard, it would be important that therapists could develop what has been defined in the literature as a metalogical point of view-that is, a postmodern point of view-in which the certainty of knowledge is doubted, and the point of view is open to alternative truths (Porpora, 2001). A metalogical point of view considers any point of view to be a product of the situation and circumstances and comes with awareness that one's point of view is as fabricated as any other. In this way, it is in a position to consider alternative orientations at pareven those based on a different frame of reference. A metalogical point of view, if applied to the clinical setting, when is able to avoid the risk of creating practices that are not directed by theory, is the only perspective that has the potential to bridge the chasm between divergent schools of psychotherapy based on differently fabricated theories.

This paper has brought to light how-despite the fact that different therapists recognize themselves

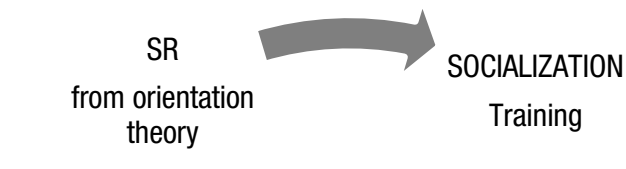

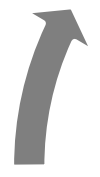

SOCIAL CHANGE

Evolution of theories

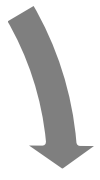

POV

Personal knowledge

General knowledge about psychology

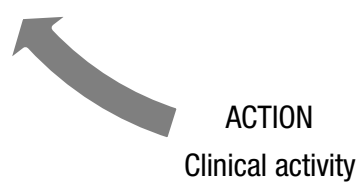

Figure 1. Social co-evolution model for psychotherapeutic tradition. $\mathrm{SR}=$ Social Representation; POV = Point of View. 
as belonging to a specific school of psychotherapy-many of our participants did express an eclectic knowledge structure. Based on this, it was possible to identify some informal styles of theory management and methods belonging to different traditions. Further studies could be carried out to confirm the appropriacy of the categories explored during this research, increasing the sample size or including psychotherapists representing theoretical models not taken into account during this pilot research. To this aim, it would be interesting to determine, also through quantitative studies, the existence of more specific predictors of the informal types of eclecticism identified; in a qualitative study such as this one, these types of results can only be summarily indicated. It would be equally worthwhile to investigate which of the knowledge structures revealed here are most able to guarantee an increase in the effectiveness of clinical therapy.

In any case, the present research intended to provide some topics for discussion, foreseeing social organization changes that in Italy, for instance, envision the introduction of psychotherapy services in public institutions. As we previously pointed out, public institutions are an important context where a therapist can negotiate meanings related to the organization of his or her therapeutic activity with other, different kinds of professionals. Such a negotiation is becoming a vital issue; however, despite the fact that empirical findings are still ambiguous regarding the matter (Barber, 2009), it is our opinion that pluralism should not become a mere clinical application of eclecticism (Duncan, Parks, \& Rusk, 1990). Moreover, discrepancies among points of view emerging from personal narrations and $S R$ from psychotherapeutic theories can prefigure actual evolutionary lines-not yet formalizedaccording to which models are already changing. It should also be mentioned that the changes in the models are related to clinical practice and to the continuous adaptation of the therapist's knowledge to the cultural and structural changes in contemporary society as well. In this sense, the gap emerging between SR and POV does not necessarily suggest poor clinical expertise in therapists; on the contrary, it can give us an opportunity for critical thinking and a full understanding of the heuristic potential of such forms of knowledge. Sometimes the therapists' contributions originated from a misunderstanding of theoretical issues-that is, were inconsistent from an epistemological perspective (Salvatore, 2011); in other cases, such contributions may represent a well-reasoned attempt to break free from what psychotherapy models risk becoming: normative institutions, inflexible toward any change. With regard to this specific issue, one therapist remarked:

We ought to distinguish between what it means to be orthodox, to be a good learner in your psychotherapy school, and to be an intellectual. ... If you are orthodox, you ought to consider a theory, understand it in depth, and practice it. If you are a good learner, you know you ought to interpret such a theory. Actually, you may also be an intellectual, you can consider all the good your psychotherapy school gave you, something good theory gave you, something good inside yourself, and take the risk to begin reasoning about it (Interview 19; female; constructivist).

As a conclusion, we quote Rosati's warning about eclecticism: "If you try to hit a nail in with a spanner, it might work if you have nothing better to use, but it would give a very bad impression if someone tried to unscrew a bolt with a hammer" (as cited in Marhaba \& Armezzani, 1988, p. 125).

\section{References}

Arnkoff, D. B. (1995). Theoretical orientation and psychotherapy integration. Journal of Counselling Psychology, 42(4), 423-425.

Barber, J. P. (2009). Toward a working trough of some core conflicts in psychotherapy research. Psychotherapy Research, 19(1), 1-12. DOI: 10.1080/10503300802609680

Berger, P., \& Luckmann, T. (1966). The social construction of reality. Harmondsworth: Penguin.

Beutler, L. E., \& Clarkin, J. F. (1990). Systematic treatment selection: Toward targeted therapeutic interventions. New York: Brunner/Mazel.

Breakwell, G. M. (2001). Social representational constraints upon identity processes. In K. Deaux \& G. Philogene (Eds), Representations of the social: Bridging theoretical traditions. Oxford: Blackwell Publishers Ltd.

Carli, R. (1987). Psicologia clinica [Clinical psychology]. Torino: Utet Libreria.

Charmaz, K. (2006). Constructing grounded theory: A practical guide through qualitative analysis. London: Sage.

Chryssides, A., Dashtipour, P., Keshet S., Righi C., Sammut, G., \& Sartawi, M., (2009). We don't share! The social representation approach, enactivism and the fundamental incompatibilities between the two. Culture \& Psychology, 15(1), 83-95. DOI: 10.1177/1354067X08096514.

Deconchy, J. P. (1984). Rationality and social control in orthodox systems. In H. Tajfel (Eds.), The social dimension: European developments in social psychology (pp. 425-445). Cambridge: Cambridge University Press.

Duncan, B. L., Parks, M. B., \& Rusk, G. S. (1990). Strategic eclecticism: A technical alternative for eclectic psychotherapy. Psychotherapy: Theory, Research, Practice, Training, 27(4), 568-577.

Elliott, R., Slatick, E., \& Urman, M. (2001). Qualitative change process research on psychotherapy: alternative strategies. In J. Frommer \& D. Rennie (Eds.), Qualitative psychotherapy research: Methods and methodology (pp. 69-111). Lengherich: Pabst Science Publishers.

Faccio, E., Centomo, C., \& Mininni, G. (2011). "Measuring up to measure" Dismorphophobia as a language game. Integrative Psychological and Behavioral Science, 45(3), 304-324. DOI: 10.1007/s12124-011-9179-2.

Faccio, E., Cipolletta, S., Dagani, J. \& Romaioli, D. (in press). Auditory hallucinations as a personal experience: Analysis of non-psychiatric voice hearers' narrations. Journal of Psychiatric and Mental Health Nursing.

Farr, R. M. \& Moscovici, S. (Eds.). (1984). Social representations. Cambridge: Cambridge University Press. 
Flick, U. (Ed.). (1998). The psychology of the social. Sage: London.

Flick, U. (2000). Episodic interviewing. In M. Bauer \& G. Gaskell (Eds.), Qualitative researching with text, image and sound: $A$ handbook (pp. 75-92). London: Sage.

Flick, U. (2006). An introduction to qualitative research (3 ${ }^{\text {rd }}$ ed.). London: Sage.

Gadamer, H. G. (1989a). Destruction and deconstruction. In D. P. Michelfelder \& R. E. Palmer (Eds.), Dialogue and Deconstruction: The Gadamer-Derrida encounter (pp. 102-113). Albany: State University of New York Press.

Gadamer, H. G. (1989b). Hermeneutics and locogentrism. In D. P. Michelfelder \& R. E. Palmer (Eds.), Dialogue and Deconstruction: The Gadamer-Derrida encounter (pp. 114-125). Albany: State University of New York Press.

Gadamer, H. G. (2000). Truth and method (2 $2^{\text {nd }}$ ed.). New York: Continuum.

Gergen, K. J. (1994). Realities and relationships: Soundings in social constructionism. Cambridge, MA: Harvard University Press.

Gergen, K. J. (2006). Therapeutic realities. London: Sage.

Gilliland, B. E., James, R. K., \& Bowman, J. T. (1994). Response to the Lazarus and Beutler article "On technical eclecticism". Journal of Counselling \& Development, 72(5), 554-555.

Glaser, B. G., \& Strauss, A. L. (1967). The discovery of grounded theory: Strategies for qualitative research. Chicago: Aldine Publishing Company.

Hansen, N. D., Randazzo, K. V., Schwartz, A., Marshall, M., Kalis, D., Frazier, R., Burke, C., Kershner-Rice, K. \& Norvig, G. (2006). Do we practice what we preach? An exploratory survey of multicultural psychotherapy competencies. Professional Psychology: Research and Practice, 37(1), 66-74. DOI: $10.1037 / 0735-7028.37 .1 .66$

Harré, R. (1984). Personal being. A theory for individual psychology. Cambridge, Mass: Harvard University Press.

Held, B. S. (1995). Back to reality: A critique of postmodern theory in psychotherapy. New York: W. W. Norton \& Co.

Hermanns, H. (2004). Interviewing as an Activity. In U. Flick, E. Kardorff \& I. Steinke (Eds.), A Companion to Qualitative Research (pp. 209-214). London: Sage.

Hickman, E. E., Arnkoff, D. B., Glass, C. R. \& Schottenbauer, M. A. (2009). Psychotherapy integration as practiced by experts. Psychotherapy: Theory, Research, Practice, Training, 46(4), 486-491 DOI: 10.1037/a0017949

Hill, C. E., Knox, S., Thompson, B. J., Williams, E. N., Hess, S. A. \& Ladany, N. (2005). Consensual qualitative research: An update. Journal of Counseling Psychology, 52(2), 196-205. DOI: 10.1037/0022-0167.52.2.196

Hoshmand, L. \& Polkinghorne, D. (1992). Redefining the science-practice relationship and professional training. American Psychologist, 47, 55-66.

Iannaccone, A.\& Ligorio, B. (2001). La Situated Cognition in Italia: Stato dell'arte [The Situated Cognition in Italy: State of the art]. Schweizerische Zeitschrift für Bildungswissenschaften 23(3), 439-452.

Jovchelovitch, S. (2008). The rehabilitation of common sense: Social representations, science and cognitive polyphasia. Journal for the Theory of Social Behaviour, 38(4), 431-448. DOI: 10.1111/j.1468-5914.2008.00378.x

Jovchelovitch, S. (2007). Knowledge in context. Representations, Community and Culture. London: Routledge.

Kelly, G. A. (1995). The psychology of personal constructs. New York: Norton.

Lazarus, A. A., Beutler, L. E., \& Norcross, J. C. (1992). The future of technical eclecticism. Psychotherapy: Theory, Research, Practice, Training, 29(1), 11-20. DOI: 10.1037/ 0033-3204.29.1.11

Lazarus, A. A. \& Beutler, L. E. (1993). On technical eclecticism.
Journal of Counselling and Development, 71(4), 381-385.

Lebart, L., Morineau, A. \& Becue, M. (1989). SPAD-T: Système Portable pour l'Analyse des Données Textuelles: Manuel de l'utilisateur. Paris: CISIA.

Marhaba, S. \& Armezzani, M. (1988). Quale psicoterapia? [Which psychotherapy?]. Padova: Liviana Editrice.

Moscovici, S. (1961). La Psychanalyse, son image et son public [Psychoanalysis: Its image and its public]. Paris: Puf.

Moscovici, S. (1976). Social influence and social change. London: Academic Press.

Moscovici, S. (2000). Social representations. Explorations in social psychology. Cambridge, UK: Polity Press.

Norcross J. C. (Eds.). (1986). Handbook of eclectic psychotherapy. New York: Brunner/Mazel.

Norcross, J. C. \& Goldfried, M. R. (Eds.). (2005). Handbook of psychotherapy integration $\left(2^{\text {nd }} \mathrm{ed}\right.$.). New York: Oxford.

Patterson, C. H. (1989). Eclecticism in psychotherapy: Is integration possible? Psychotherapy: Theory, Research, Practice, Training, 26(2), 157-161.

Porpora, D. V. (2001). Landscapes of the soul: The loss of moral meaning in American life. Oxford: Oxford University Press.

Prochaska, J. \& DiClemente, C. (1984). The transtheoretical approach: Crossing traditional boundaries of therapy. Homewood, Ill: Dow Jones-Irwin.

Riessman, C. K. (1993). Narrative analysis. London: Sage.

Roberts, M. C. (2006). Essential tension: Specialization with broad and general training in psychology. American Psychologist, 61(8), 862-870. DOI: 10.1037/0003-066X.61.8.862.

Romaioli, D. (2012). Opening scenarios: a relational perspective on how to deal with multiple therapeutic views. Psychological Studies, 57(2), 195-202. DOI: 10.1007/ s12646-011-0101-2.

Romaioli, D. \& Contarello, A. (2012). How do therapists understand their client's problem and its resolution: Objectification in theories of change. Journal of Contemporary Psychotherapy, 42(2), 93-100. DOI: 10.1007/s10879 -011-9188-y.

Romaioli, D., Faccio, E. \& Salvini, A. (2008). On acting against one's best judgement: A social-constructionist interpretation for the akrasia problem. Journal for the Theory of Social Behaviour, 38(2), 179-192. DOI: 10.1111/ j.1468-5914.2008.00365.x.

Romano, D. F. \& Quaglino, G. P. (2001). Nuove lauree e nuove professioni: Per una scelta o solo per editto? [New degrees and new professions: For a choice or for edict?]. Giornale Italiano di Psicologia, 28(2), 241-250. DOI: 10. $1421 / 343$

Sammut, G. \& Gaskell, G. (2010). Points of view, social positioning and intercultural relations. Journal for the Theory of Social Behavior, 40, 47-64. DOI: 10.1111/j.14685914.2009.00422.x

Salvatore, S. (2006). Models of knowledge and psychological action. Rivista di Psicologia Clinica, 2-3, 121-134. Retrieved from http://www.rivistadipsicologiaclinica.it/ english/index_eng.htm

Salvatore, S. (2011). Psychotherapy research needs theory: Outline for an epistemology of the clinical exchange. Integrative Psychological and Behavioral Science, 45(3), 366388. DOI: $10.1007 / \mathrm{s} 12124-011-9180-9$.

Slife, B. D. (1987). The perils of eclecticism as therapeutic orientation. Theoretical and Philosophical Psychology, 7(2), 94-103.

Slife, B. D. \& Reber, J. S. (2001). Eclecticism in psychotherapy: Is it really the best substitute for traditional theories? In B. D. Slife, R. N. Williams \& S. H. Barlow, (Eds.), Critical Issues in Psychotherapy: Translating New Ideas into Practice (pp. 213-233). Thousand Oaks, CA: Sage Publications.

Strauss, A. L. \& Corbin, J. (1998). Basic of Qualitative Re- 
search ( $2^{\text {nd }}$ ed.). London: Sage.

Tateo, L. \& Iannacone, A. (2011). Social representations, individual and collective mind: A study of Wundt, Cattaneo \& Moscovici. Integrative Psychological and Behavioral Science, 46(1), 57-69. DOI: 10.1007/s12124-011-9162-y

Thommen, B., Ammann, R. \& von Cranach, M. (1988). Handlungsorganisation durch soziale Repraesentationen: Welchen Einfluss haben therapeutische Schulen auf das Handeln ibrer Mitglieder? [Organization of action by social representations: Which influence do therapeutic schools on the actions of their members]. Bern: Huber.

Tomm, K. (1987). Interventive Interviewing: Part I. Family Process, 26, 3-13.

Tulving, E. (1972). Episodic and semantic memory. In E. Tulving \& W. Donaldson (Eds.), Organization of memory (pp. 381-403). New York: Academic Press.

Tsirogianni, S. \& Gaskell, G. (2011). The role of plurality and context in social values. Journal for the Theory of Social Behaviour, 41(4), 441-465. DOI: 10.1111/j.1468-5914.2011.00470.x

Tsirogianni, S. \& Andreouli, E. (2011). Beyond social cohesion: The role of 'fusion of horizons' in inter-group solidarities. Papers on Social Representations, 20, 5.1-5.25. Retrieved from http://www.psych.lse.ac.uk/psr/

Valsiner, J. \& Van Der Veer, R. (2000). The social mind: Con- struction of the idea. New York, Us: Cambridge University Press.

Valsiner, J. (2003). Enabling a theory of enablement: In search for a theory-method link. Papers on Social Representations, 12, 121-128.

von Cranach, M., Mugny, G, \& Doise, E. (Eds.). (1992). Social representation and the social bases of knowledge. Lewiston NY: Hogrefe \& Huber Pub.

von Cranach, M. \& Harré, R. (1982). The analysis of action: Recent theoretical and empirical advances. Cambridge: Cambridge University Press.

Wagner, W., Duveen, G., Verma, J. \& Themel, M. (2000). I have some faith and at the same time I don't believe: Cognitive polyphasia and cultural change in India. Journal of Community \& Applied Social Psychology, 10, 301314. DOI: 10.1002/1099-1298(200007/08)10

Wagner, W. \& Hayes, N. (2004). Everyday knowledge and common sense: The theory of social representations. New York: Palgrave Macmillian.

Received April 9, 2012

Revision received October 5, 2012

Accepted October 6, 2012 